\title{
RELIABILITY OF RC FRAME-BRACED SYSTEMS IN DANGEROUS GEOLOGICAL CONDITIONS
}

\author{
Yemelyanov Sergey Gennadyevich, Ekaterina Gennadievna Pakhomova, Ksenia Olegovna Dubrakova* \\ Southwest State University, Kursk, Russia
}

The paper considers influence of sudden transformations, linked with foundation, to reliability of reinforced concrete structural systems at buckling one of load bearing elements. Authors investigated influence of deformation value to bifurcation type for each leg of building frame. It was determined subsidence value that leads to changing of bifurcation type for rod elements of the system.Authors shown a suggested criterion for stability assessment of compressed rod elements of structural systems operated in dangerous geotechnical conditions. Such criterion can be used for assessment residual resource of a building at special impacts linked with foundation subsidence under one support.

Keywords: Subsidence soils, Frame-rod systems, Performance, Stability, Emergency

\section{INTRODUCTION}

Regions with subsidence foundations are widely distributed through the territory of Russia and neighbor countries. However the most dangerous ground conditions of the II subsidence type does not exceed $10 \%$ of all area.

Experience of investigation of subsidence foundation accumulated in Russia and other countries shows underestimation of calculation subsidence deformations in comparison with real ones about 1.5...2.3 times [5; 7; $11 ; 12]$.At the same time, in the last years in accordance with environmental and artificial dangerous and significant deterioration of facilities in our country, the Federal law No 384-FZ "Technical regulations on the safety of buildings and structures" was accepted. This regulatory document presents new requirements for functional and structural solutions in accordance with new parameters of operational power and environmental impacts and possible accidental impacts on facilities [6; 9; 13]. However in order to explain these new requirements of the Federal law, it is necessary to provide advanced researches to investigate various accidental impacts, in particular, impacts linked with foundation subsidence.

In addition to calculation of load bearing capacity of structures operating in dangerous geotechnical conditions, researches on reliability of frame-braced systems at a support subsidence are actual problem.

Consequently, in order to satisfy new requirements of the Federal law, it is necessary to provide advanced researches of different accidental impacts, in particular, linked with foundation subsidence and it affecting to stability of each element as well as entire structural system.

Sudden structural transformations significantly, caused by foundation subsidence, affect to reliability parameters of reinforced concrete structural systems at buckling of load bearing elements [15; 16]. Such overcritical impacts accompanying with changes of geometry cause changes of critical parameters and corresponding critical forces.

At the same time an important question in solution to stability problem of structural systems at accidental impacts is determining of the most dangerous elements or structural parts with low resistance to buckling $[1 ; 2$; 3]. Therefore, at first stability analysis should be provided for entire structural system, i.e. first level calculation model should be constructed initially. Using such model, we provide analysis of stress state of all elements which require advanced investigation.

First level calculation can be carried out with elastic model since the main purpose of this calculation is assessment of stress state of entire system and finding of the most dangerous elements.

\section{DEFINING EQUATIONS}

Figure 1 shows rod excluded from rod system that loss stability.It additional deformation energy that caused by bifurcation equals to sum of works of ends' axial and shear forces and bending moments. Let us represent it as two parts [10; 17-19]:

$$
\mathrm{U}_{\mathrm{i}}=\mathrm{A}_{\mathrm{i}}\left(\mathrm{N}_{\mathrm{i}}\right)+\mathrm{A}_{\mathrm{i}}\left(\mathrm{M}_{\mathrm{i}}, \mathrm{Q}_{\mathrm{i}}\right),
$$

where $A_{i}\left(N_{i}\right)=N_{i} \Delta_{i}$ is work of axial compressing forces for convergence $\Delta_{i}$ of points it attaching,

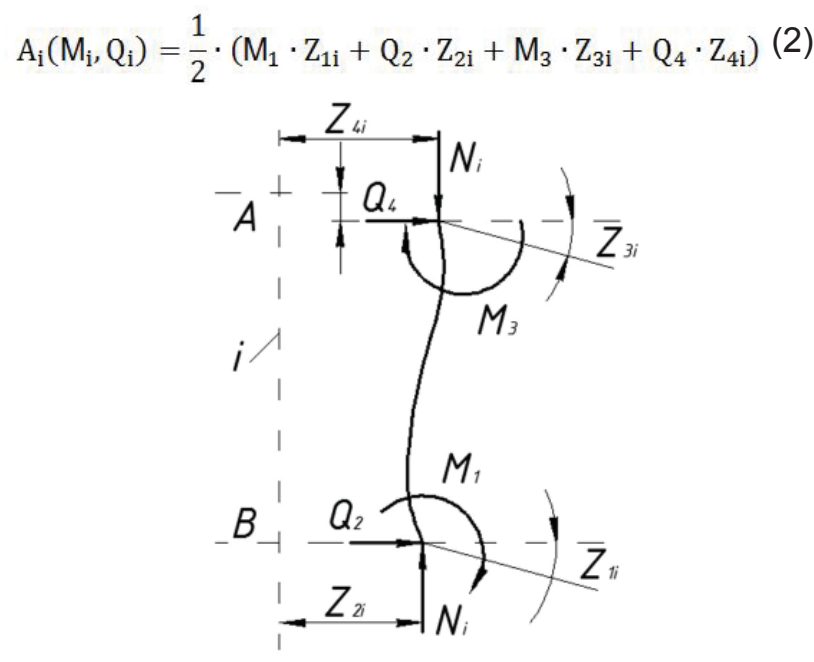

Figure 1: A rod excluded from a system 
Since overall energy of system is more than null $U_{i}>0$, then works' sum (1) always is positive. However signs of components $A_{i}\left(N_{i}\right)$ and $A_{i}\left(M_{i}, Q_{i}\right)$ can take the same or opposite signs. For compressing force it work for convergence of points is positive $A_{i}\left(N_{i}\right)>0$,i.e. it contributes to active rod bifurcation. Work of ends' moments and shear forces $A_{i}\left(M_{i}, Q_{i}\right)$ for given loading scheme can be more, less or equal to null $[1 ; 2 ; 3]$.

In the first case it means that work of axial force $\mathrm{N}_{i}$ is not enough to compensate increment potential energy of rod deformation and neighbor elements (as support reactions) contribute to it buckling. It is case of "passive" or "coerced" bifurcation. Case, when work of moments and shear forces is negative $A_{i}\left(M_{i}, Q_{i}\right)<0$, presents, that neighbor elements resist to it it bifurcation and, consequently, rod loss stability "actively" involving in this process overall system $[1 ; 2 ; 3]$.

When work of moments and shear forces equals to null $A_{i}\left(M_{i}, Q_{i}\right)=0$, state ofi -th rod and all system is equally stable. Consequently, sign of work (2) may be used as criterion of assessment of type of rod buckling. At the same time inequality:

$$
\mathrm{A}_{i}\left(\mathrm{M}_{i}, \mathrm{Q}_{i}\right)<0
$$

is attribute of "active" bifurcation of this rod for given loading scheme, and inequality:

$$
\mathrm{A}_{i}\left(\mathrm{M}_{i}, \mathrm{Q}_{i}\right)>0
$$

is attribute of "passive" bifurcation. Equality:

$$
A_{i}\left(M_{i}, Q_{i}\right)=0
$$

Is attribute of equally stable state of rod and frame. Values of work $A_{i}\left(M_{i}, Q_{i}\right)$, representing the energy contributions of the neighbor elements to the bifurcation of each i-th rod, give quantity assessment of active or passive bifurcation of considering rod (or some part of a system).

In the case of accidental impact linked with foundation subsidence under column footing, work of axial force can change it sign $A_{i}\left(N_{i}\right)<0$, ceasing to contribute to active bifurcation of the rod. Work of ends' reactions $A_{i}\left(M_{i}, Q_{i}\right)$ does not change it values in this case.

It is necessary to obtain criterion for assessment of bifurcation for case of accidental impact linked with foundation subsidence. Such criterion should allow describing behavior whether one element or entire system.

For rod elements subjected to active bifurcation, expression (6) becomes a bifurcation criterion, that allows evaluating possibility of bifurcation type changing (from active to passive).

$$
\left|A_{i}(N)\right|>\left|A_{i}\left(M_{i}, Q_{i}\right)\right|
$$

Accounting sign of work, expression (6) can be written as follows:

$$
\mathrm{A}_{i}(\mathrm{~N})+\mathrm{A}_{i}\left(\mathrm{M}_{i}, \mathrm{Q}_{i}\right)>0
$$

Expression (7) takes in account work of axial force for displacement of support in the case of foundation subsidence:

$$
\mathrm{A}^{\prime}{ }_{\mathrm{i}}(\mathrm{N})=\mathrm{S}_{\mathrm{sl}} \cdot \mathrm{P}_{k p}
$$

$$
\mathrm{S}_{\mathrm{sl}} \cdot \frac{v^{2} \cdot i}{l^{2}}+\mathrm{A}_{\mathrm{i}}\left(\mathrm{M}_{\mathrm{i}}, \mathrm{Q}_{\mathrm{i}}\right)>0 .
$$

\section{QUANTITATIVE ANALYSIS}

Let us consider two span frame in which central leg and outer legs loaded with forces Pcr (fig. 2a). Let us determine bifurcation type for rod (active or passive).In order to calculate frame, we used quasi-static method, displacement method and step-iteration procedure.

(a)

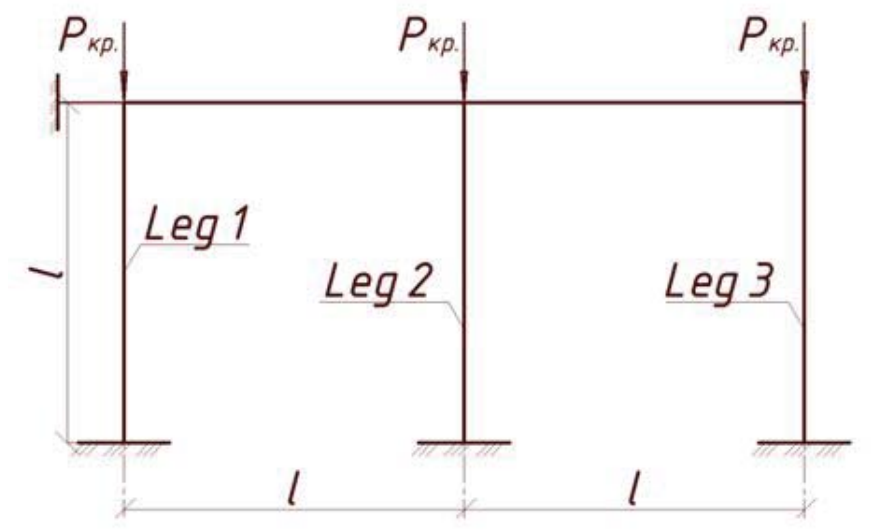

(b)

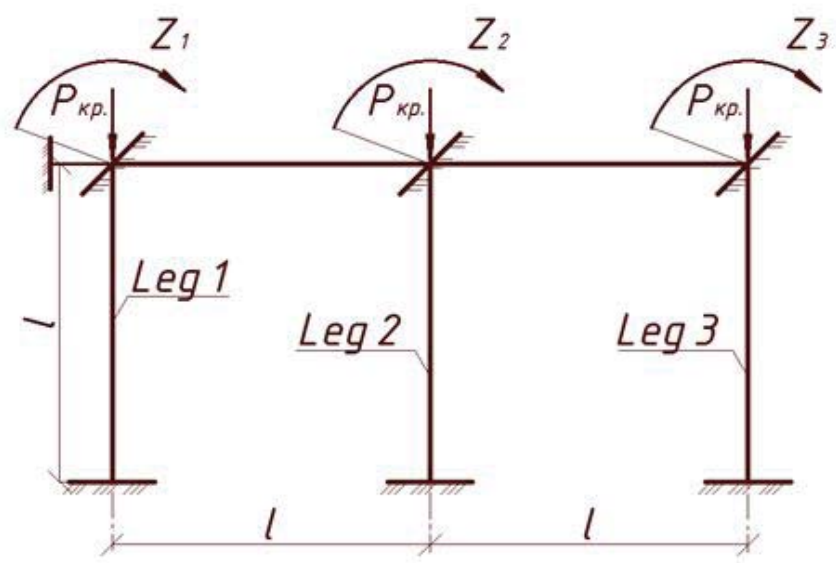

Figure 2: Calculation scheme for frame (a) and equivalent system of the displacement method (b)

We performed calculations of works of ends' moments and shear forces using special functions of the displacement method.If we accept rotation angles as variables Z1, Z2, Z3 (fig. 4.6), homogenous system of equations takes the form:

$$
\left.\begin{array}{l}
\mathrm{r}_{11} \cdot Z_{1}+\mathrm{r}_{12} \cdot Z_{1}+\mathrm{r}_{13} \cdot Z_{3}=0 \\
\mathrm{r}_{21} \cdot Z_{1}+\mathrm{r}_{22} \cdot Z_{1}+\mathrm{r}_{23} \cdot Z_{3}=0 \\
\mathrm{r}_{31} \cdot Z_{1}+\mathrm{r}_{32} \cdot Z_{1}+\mathrm{r}_{33} \cdot Z_{3}=0
\end{array}\right\}
$$

Where

$$
\begin{aligned}
& r_{11}=8 \cdot i+4 \cdot i \cdot \varphi_{2}\left(v_{1}\right) \\
& r_{22}=8 \cdot i+4 \cdot i \cdot \varphi_{2}\left(v_{2}\right) \\
& r_{33}=4 \cdot i+4 \cdot i \cdot \varphi_{2}\left(v_{3}\right) \\
& r_{12}=r_{23}=2 \cdot i ; r_{13}=r_{31}=0 ; v_{i}=l \cdot \sqrt{\frac{P_{i}}{B_{\text {red }}}},(i=1,2,3) .
\end{aligned}
$$




$$
\begin{aligned}
& \operatorname{Det}=\left(8 \cdot i+4 \cdot i \cdot \varphi_{2}\left(v_{1}\right)\right) \cdot\left(8 \cdot i+4 \cdot i \cdot \varphi_{2}\left(v_{2}\right) \cdot\left(4 \cdot i+4 \cdot i \cdot \varphi_{2}\left(v_{3}\right)\right)+16 \cdot i^{3}-\right. \\
&\left(8 \cdot i+4 \cdot i \cdot \varphi_{2}\left(v_{1}\right)\right) \cdot 4 \cdot i^{2}-4 \cdot i^{2} \cdot\left(4 \cdot i+4 \cdot i \cdot \varphi_{2}\left(v_{3}\right)\right) . \\
& 8 \cdot\left[\left(2+\varphi_{2}\left(v_{1}\right)\right) \cdot\left(2+\varphi_{2}\left(v_{2}\right)\right) \cdot\left(1+\varphi_{2}\left(v_{3}\right)\right)\right]-2 \cdot\left[3++\varphi_{2}\left(v_{1}\right)+\varphi_{2}\left(v_{3}\right)\right]=0 .
\end{aligned}
$$

where $\mathrm{B}_{\text {red }}$ is reduced stiffness of rod cross section; $v_{i}$ is parameter of secular equation.

Determinant of the system (10) can be found from following expression.

After transformation of expression (11), characteristic equation for critical force $P_{c r}(\mathrm{w}, \mathrm{t})$ takes the form. Further let us determine unknown values of rotation angles and displacements Z1, Z2, Zn. For investigated rod system we carried out plotting of diagram of internal power factors: bending moments, axial and shear forces. Let us find value of determinant of the system of canonic equations of the displacement method that depend on parameter of secular equation $v_{i}$. Using iteration method for each rod element of structural system we determine initial parameter of secular equation $\mathrm{v}_{\mathrm{i} 0}$, for which determinant equals to null.

Applying mentioned equations, we find critical parameters and modes of buckling for considering system. It is interesting assessment of accidental impact (foundation subsidence under one of the supports) affecting to bifurcation character of rods of the structural system. Really it may expect that power factors in condition of foundation subsidence cause changing of passive type of bifurcation to active or conversely, i.e. inequality $A_{i}<0$ or $A_{i}>0$ changes it sign respectively.

In order to solve this problem, we find length factors of frame legs and work of bending moments and shear forces for the primary scheme. Work of each frame leg equals:

$$
A_{i}\left(M_{i}, Q_{i}\right)=2 \cdot i \cdot \varphi_{2, i} \cdot Z_{i}
$$

For the first leg: $A_{1}\left(M_{1}, Q_{1}\right)=-0,293 \cdot i$, work of ends' moments and shear forces the second leg: $\mathrm{A}_{2}\left(\mathrm{M}_{2}, \mathrm{Q}_{2}\right)=-0,723 \cdot i$, the third leg: $\mathrm{A}_{3}\left(\mathrm{M}_{3}, \mathrm{Q}_{3}\right)=1,526 \cdot i$. Consequently, the first and the second frame leg loss stability actively, third - passively.

Let us consider accidental impact subjected by foundation subsidence under the first leg. Work of axial force executing at support displacement partially compensates work for convergence of end sections of the element.In this case mentioned work should be taken in account for assessing of compressed legs' stability. Inequality (14) becomes criterion of active bifurcation of rod element.

$$
A_{i}\left(M_{i}, Q_{i}\right)+A_{i}^{\prime}\left(N_{i}\right)<0,
$$

Where $A_{i}^{\prime}\left(N_{-} i\right.$ )is component of axial forceN_iwork for leg displacement in the case of emergency situation appearing (foundation subsidence).

Analyzing expression (14), we determine critical value of subsidence $S_{\text {sl,kp. }}$, when leg 1 of considering frame transmit to passive bifurcation state changing process loss of stability for entire system:

$$
\mathrm{S}_{\mathrm{sl}, \mathrm{kp} .}=\frac{\mathrm{A}_{\mathrm{i}}\left(\mathrm{M}_{\mathrm{i}}, \mathrm{Q}_{\mathrm{i}}\right)}{P} \text {, }
$$

Taking in account work of the first $\operatorname{leg} \mathrm{A}_{1}\left(\mathrm{M}_{1}, \mathrm{Q}_{1}\right)=-0,293 \cdot \mathrm{i}$ :

$$
\mathrm{S}_{\mathrm{sl}, \mathrm{kp} .}>\frac{0,293 \cdot l^{2}}{v^{2}} .
$$

In order to illustrate expression (16), figure3 (a) shows dependence between critical subsidence value $S_{\text {sl,kp. }}$ and leg length and coefficient of axial bending. Figure3 (b) presents analysis of dependence of $S_{\text {sl,kp. }}$ from leg length for coefficient values $v=5,2$ and $v=4,8$.

Let us analyze behavior of legs of considering frame during buckling process before and after accidental impact linked with foundation subsidence under the first leg for element's length $l=3 \mathrm{~m}$. As it was presented above, the first and the second legs of the frame buckling actively, third - passively. Figures show active bifurcation with solid line and passive - with dashed line. For foundation subsidence under support of the first leg more than $8 \mathrm{~cm}$ bifurcation for corresponding element changes its type (fig. 4 b). At the same time leg 3 of considering frame transmits to active bifurcation.

(a)

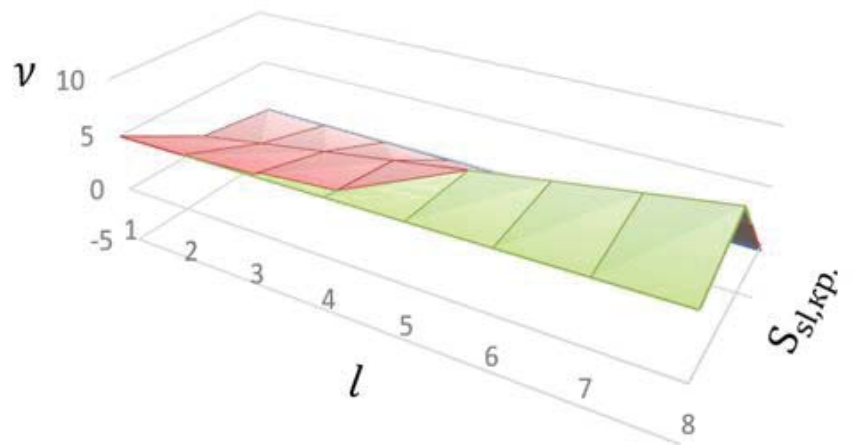

(b)

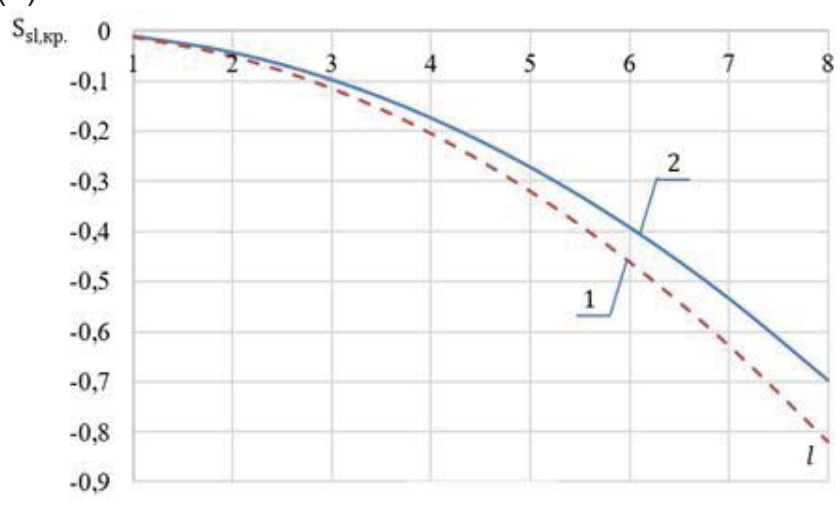

Figure 3: Dependence between critical subsidence value $S_{s l, k p .}$ and two parameters: omдвухпараметров: leg length and coefficient of axial bending (a), dependence from one parameter: leg length (b) for coefficient values $v=4,8(1)$ and $v=5,2(2)$ 
(a)

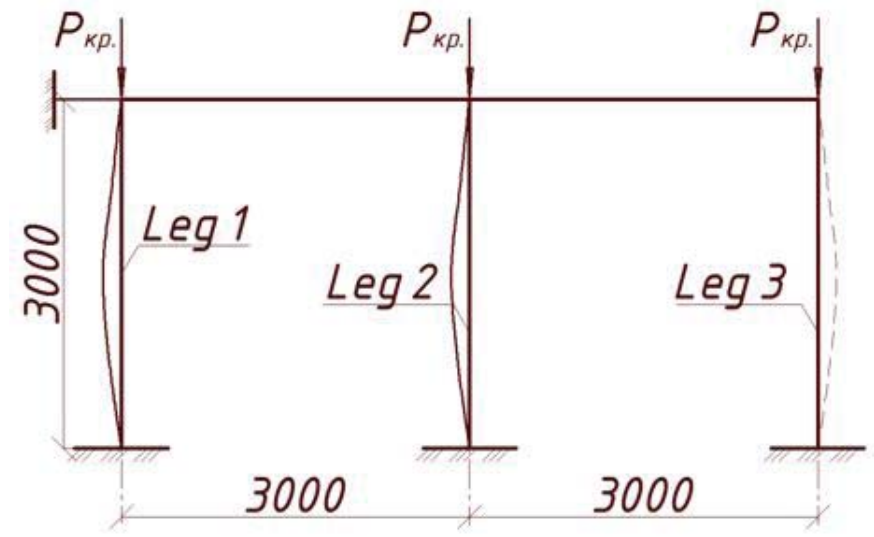

(b)

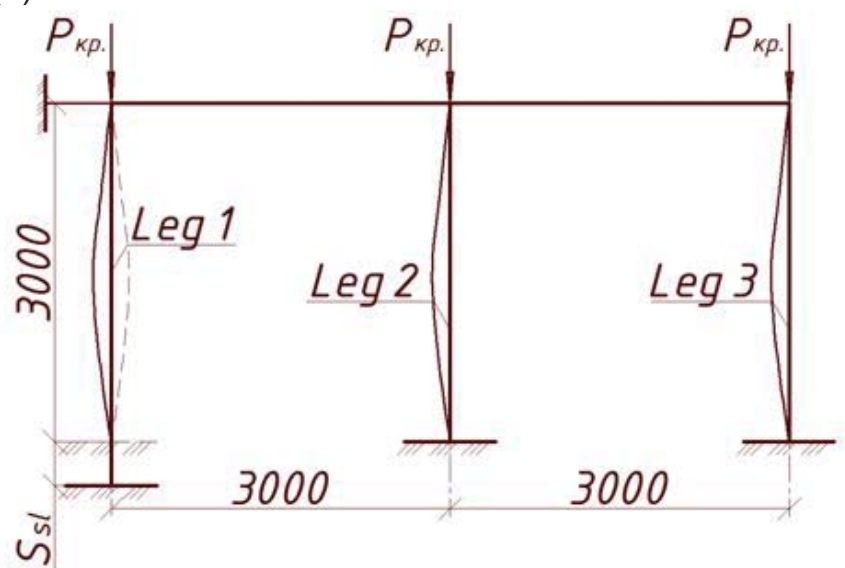

Figure 4: Modes of frame buckling before (a) and after emergency situation(b)

\section{IMPLEMENTATION RESULTS}

Suggested technique of reliability analysis for reinforced concrete frame-braced at emergency situation linked with foundation subsidence under one of the legs is implemented in Southwest state University for designing of public building in Kursk.Design static calculation of finite element model presented in figure 5 , a is carried out using software SCAD. Critical parameters (fig. 5, b) are determined for the most loaded building frame fragment. These parameters characterize buckling process for system and changing of bifurcation type for legs at considering emergency situation.Secondary calculation model loaded with external concentrated loads determined with SCAD software.

Let us analyze legs' behavior of the most loaded building frame fragment of considering building during buckling before and after emergency situation linked with foundation subsidence under all supports (figure 6).

As it is shown in figure $6(a)$, before considering emergency situation the first and the third legs of building frame loss stability passively, and the second one - actively. After foundation subsidence under the second support bifurcation of elements do not change its type (fig. 4, b). At the same time similar failure with leg 1 for deformation value more than 13 cmleads to buckling mode changing for the first and the second elements. (a)

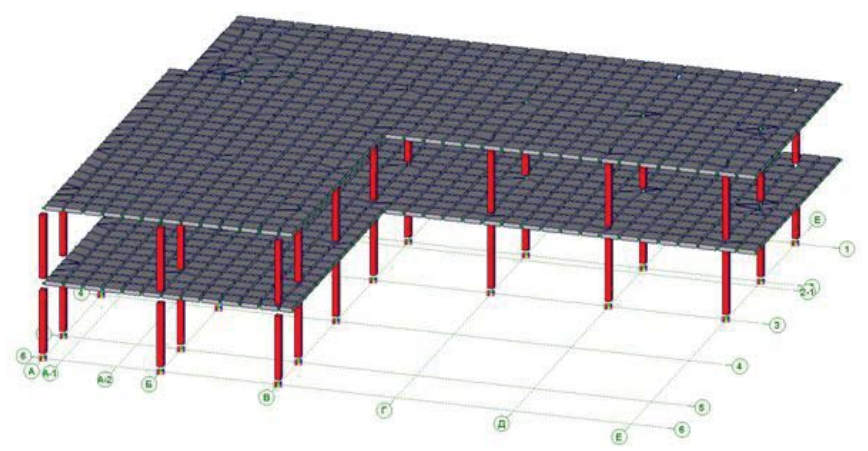

(b)

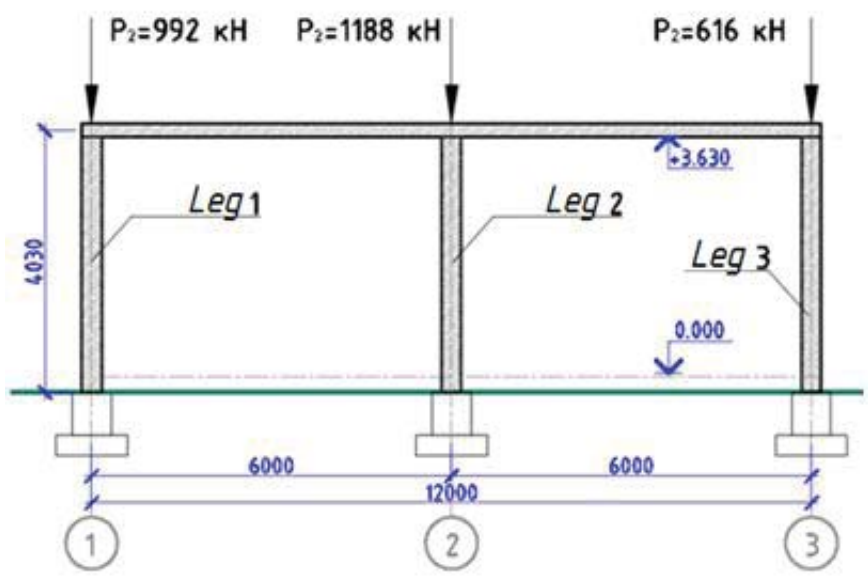

Figure 5: Finite element model for building frame (a); structural scheme

конструктивнаясхемафрагментакаркасаздания (b)

(a)

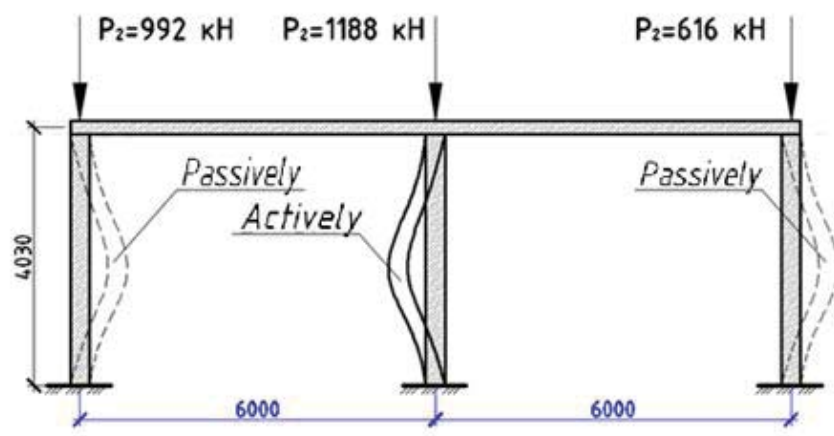

(b)

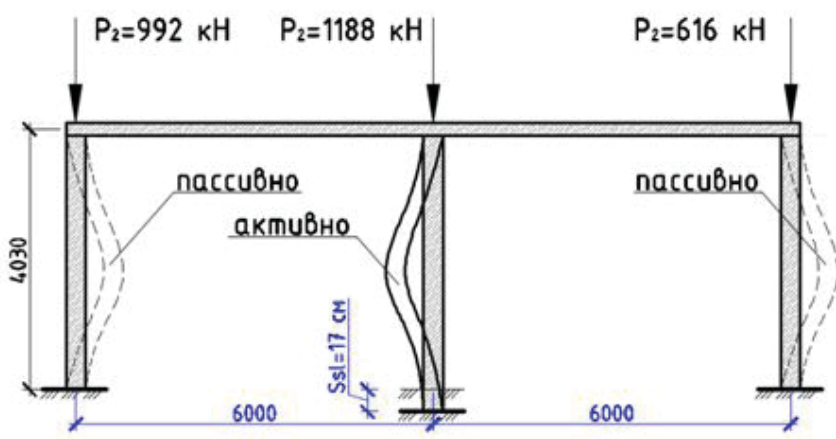


(c)

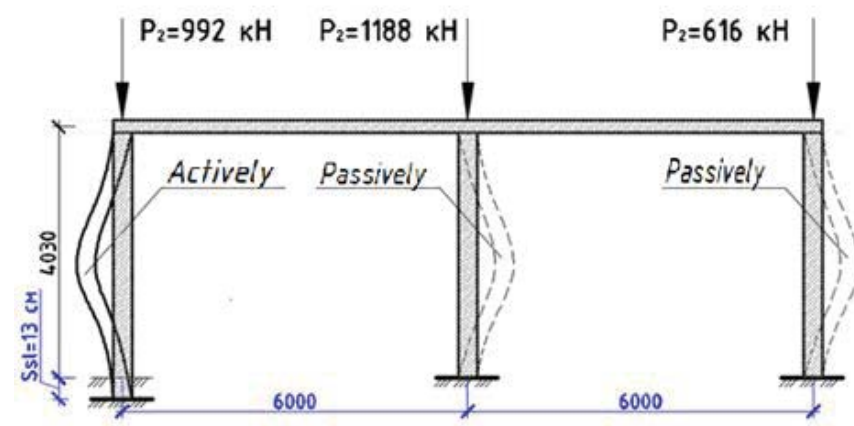

(d)

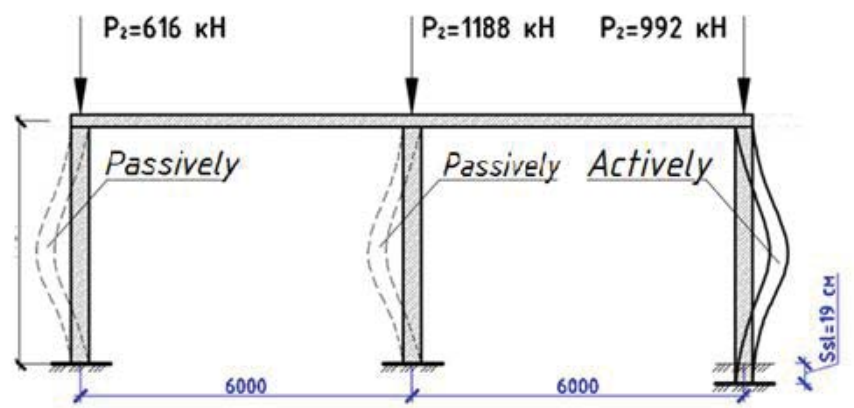

Figure 6: Buckling modes for building frame legs before (a) and after foundation subsidence under the first (b), the second (c) and the third (d) supports

\section{CONCLUSIONS}

Suggested criterion for assessing stability of compressed elements of structural systems, operating in dangerous geotechnical conditions, allows to provide respectively simple evaluation of resistance resource of such elements for emergency situations linked with foundation subsidence under one of the supports. Analysis of obtained results shows that bifurcation type whether of the elements or entire system can be changed for some value of subsidence.

\section{REFERENCES}

1. Aleksandrov, A.V. Investigation of the sustainability of structures of the arch covering of the hall using the criteria for identifying the most dangerous elements / A.V. Aleksandrov, V.I. Travush, A.V. Matveev // Bulletin of the Department of Building Sciences RAACS. - 2004. - Vol. 8. - pp. 14-21.

2. Aleksandrov, A.V. Criteria for identifying the most dangerous elements and their use in problems of structural stability / A.V. Aleksandrov, A.V. Matveev // Safety of train traffic: Tr. 4th scientific-practical. conf. - M .: MIIT, 2003. - P. III - 1- III - 2 .

3. Aleksandrov, A.V. On the calculation of stability of core structures / A.V. Alexandrov, V.I. Travush, A.V. Matveev // Industrial and Civil Construction. - 2002. - № 3.- p. 16-20.
4. Aleksandrov, A. V. The role of individual elements of the core system in the event of loss of stability / A. V. Aleksandrov // Bulletin of Moscow Institute of Railway Transport. - 2001. - Vol. 5. - p. 46.

5. BagdasarovYu.A. On the reliability of land subsidence assessment / Yu.A.Bagdasarov // Foundations, foundations and soil mechanics. -2000 -№ 2. P. 2126.

6. Burenin V.S. Study of modern trends in the design of residential buildings in Russia and abroad / V.S. Burenin, V.A. Yezersky, P.V. Monastyrev // Architecture and time. - 2017. - №5. Pp. 2-6.

7. Grigoryan A.A. On the quantitative assessment of subsidence / A.A. Grigorian // Bases, foundations and soil mechanics. -2001. -№ 2. Pp. 17-21.

8. Dubrakova KO. Issues of stability of statically indefinable systems of wood / K.O. Dubrakova // BST: Bulletin of construction equipment. - 2018. - №11. Pp. 54-55.

9. Kolchunov, V.I. On the algorithmization of the problems of calculating the survivability of reinforced concrete frames with the loss of stability / V.I. Kolchunov, N.O. Prasolov, L.V. Kozharinova, O.A. Vetrova // Construction and Renovation. - 2012. №6. Pp. 28-34.

10. Matveev, A. V. Some issues of creating a specialized software complex for the analysis of bridge structures / A. V. Matveev // VestnikMIITa. - 2002. - Vol. 7. - p. $76-83$

11. Mezherovsky V.A. Moisture distribution and development of subsidence deformations in the loess base of a building / V.A. Mezherovsky // Grounds, foundations and soil mechanics. -1998. -№1. Pp. 20-22.

12. Mezherovsky V.A. Design models of the "building loess subsiding base" system / V.A. Mezherovsky // Grounds, foundations and soil mechanics. -2001. -№5.- pp. 21-23.

13. Osovskikh E.V. Evaluation of the constructive safety of monolithic cages, taking into account the dynamic effects / E.V. Osovskikh, V.M. Tolmacheva, E.G. Pakhomova, V.V. Kovalev, V.Yu. Amelin // Proceedings of South-West State University. - 2016. - №1. Pp. 96-101.

14. Pakhomova E.G. Probabilistic patterns of occurrence of building flow failures / E.G. Pakhomova, N.V. Bredikhin // Proceedings of South-West State University. - 2016. - №1. Pp. 35-40.

15. Pakhomova E.G. Durability of reinforced concrete structures of engineering structures under the influence of aggressive media / E.G. Pakhomova, E.O. Pereverzev, D.F. Konorev // Proceedings of SouthWest State University. Series: equipmentandtechnologies .- 2014. -№1. Pp. 72-74. 
16. Pakhomova E.G. Calculation of the bearing capacity of bent reinforced concrete structures with corrosion damage / E.G. Pakhomova // Industrial and civil construction. - 2009. - №5. Pp. 43-44.

17. Pyatikrestovsky K.P. The study of complex stress states of elements filling the cells between the ribs of wooden large-span domes/ Pyatikrestovsky K.P., Sokolov B.S.// International Journal for Computational Civil and Structural Engineering, 2019. T. 15. № 1.C.140-152.

18. Travush, V.I. The stability of compressed rods of wood with the simultaneous manifestation of power and environmental impact / V.I. Travush, V.I. Kolchunov, K.O. Dmitriev // Construction mechanics and calculation of structures. - 2016. - №2.Pp. 50-53.

19. Travush, V.I. Experimental and theoretical study of the strength and stability of compressed wood rods under power and environmental impact / V.I. Travush, V.I. Kolchunov, K.O. Dmitriev // Proceedings of higher educational institutions. Technology textile industry. - 2016. - №3. Pp. 280-285. 